\title{
The molecular pathogenesis of down syndrome-associated diseases and the promising potential therapeutic targets
}

\author{
Mohammed Rachidi \\ Molecular Genetics of Human Diseases (MGHD), French Polynesia and University Paris 7 Denis Diderot, Paris, France
}

Trisomy 21, the most common origin of Down syndrome, is an extra copy of chromosome 21 in all cells generated by a chromosomal non-disjunction during meiosis. The increased transcription of the oncogenes and tumor suppressor genes located on the human chromosome 21 determines transcriptional alterations of several molecular pathways involved in the Down syndrome associated diseases related to cell cycle alteration, leukemia, tumors and cancer. The elucidation of the molecular mechanisms involved in the Down syndrome-associated diseases could promise potential therapeutic targets.

Trisomy 21 or Down syndrome determined by the triplication of human chromosome 21, is the most frequent genetic disorder with hard impact on public health. The genetic overdosage, caused by the trisomy 21, determines transcriptional alterations of most genes on human chromosome 21 and their overdosage determine transcriptional variations of several genes located on other chromosomes affecting several molecular pathways involved in cell cycle alteration, leukaemia, tumors and cancer [1].

The increased transcription of the oncogenes and tumor suppressor genes located on the human chromosome 21 have important roles in leukemia, tumors and cancer that are related to cell cycle alterations. The chromosome 21 oncogene AML1 (Acute myeloid leukaemia 1) also known as RUNX1 or CBFA2 is an established regulator of hematopoiesis and megakaryopoiesis and the hereditary loss-offunction mutations of AML1 cause the autosomal dominant familial platelet disorder with a predisposition to develop acute myeloid leukemia as is also seen in mouse models [2,3]. AML1 transcripts are downregulated in Down syndrome megakaryoblasts compared to non-Down syndrome megakaryoblasts suggesting that AML1 is linked to the megakaryocytic lineage [4]. It was found that AML1 inhibits NF- $\kappa B$ signaling through interaction with I $\kappa B$ kinase complex in the cytoplasm and that the inhibition of NF- $\kappa B$ signaling in leukemic cells with mutated AML1 efficiently blocks their growth and development of leukemia. This suggest AML1 function as a cytoplasmic attenuator of NF- $\mathrm{kB}$ signaling in the repression of myeloid tumors and indicate that NF- $\mathrm{KB}$ signaling is one of the promising therapeutic targets of hematologic malignancies with AML1 abnormality [5].

The chromosome 21 gene TIAM1 (T-cell lymphoma invasion and metastasis 1) has been identified to have important roles in the progression of epithelial cancers. In human breast carcinomas, a close correlation was observed between increased TIAM1 expression and increased tumor grade [6] suggesting that increased TIAM1 expression and/or activity may promote progression of breast carcinoma. Tumors that do occur in Tiam mutant mice are more likely to progress suggesting that, in skin carcinogenesis, Tiam1 is an inhibitor of tumor development [7]. Colon carcinoma cell lines selected for increased metastatic potential in nude mice express more TIAM1 protein than their parental line $[8,9]$. This indicate that TIAM1 may have a role in the progression and metastasis of colon carcinomas and that TIAM1 regulates cell adhesion, migration and apoptosis in colon tumor cells. RNA interference (RNAi) study examined the effect of the inhibition of TIAM1 expression on proliferation and metastasis and it has been found that the silencing of TIAM1 resulted in the effective inhibition of in vitro cell growth and of the invasive ability of colorectal cancer cells. This suggest that TIAM1 plays a causal role in the metastasis of colorectal cancer and that RNAi-mediated silencing of TIAM1 may provide an opportunity to develop a new treatment strategy for colorectal cancer [10]. TIAM1 mRNA and protein levels were significantly elevated in 9 human hepatoma cell lines compared to the normal primary human hepatocyte suggesting that TIAM1 overexpression in malignant neoplasms could be a novel effective biomarker for tumors including hepatocellular carcinoma [11]. TIAM1 expression is frequently up-regulated in breast cancer and correlated with clinicopathological parameters, suggesting that TIAM1 may be a useful prognostic biomarker and potential therapeutic target for patients with breast cancer [12].

The chromosome 21 gene SIM2 (single minded 2) is one member of transcriptional repressors family involved in the neuronal differentiation and cell growth [13]. The overexpression of SIM2 was associated with tumors of the colon, pancreas and prostate $[14,15]$. The antisense inhibition of SIM2 expression in a colon cancer cell line resulted in inhibition of gene expression, growth inhibition and induction of apoptosis in vitro as well as inhibition of tumor growth in nude mouse tumoriginicity models. The induction of apoptosis by the antisense SIM2 could involve a block of cell cycle, induction of differentiation or the activation of apoptotic cascades [14] and the effect of SIM2 antisense on tumor cell apoptotic regulation [16] and inhibition of cell cycle by SIM2 [17] indicate that inhibition of tumor growth by antisense blocking of SIM2 in colon cancer may be due to an influence on cell cycle regulation. This identified the critical SIM2 gene as a drug therapy target for solid tumors and pancreatic cancer. In addition, SIM2 has been identified as a potential biomarker and immunotherapy target in prostate cancer $[18,19]$ and a predictive biomarker for uterine cervical squamous cell carcinoma [20].

Correspondence to: Mohammed Rachidi, Molecular Genetics of Human Diseases (MGHD), French Polynesia and University Paris 7 Denis Diderot, Paris, France, E-mail: rachidi.med1@yahoo.com

Received: January 03, 2018; Accepted: January 13, 2018; Published: January 16, 2018 
Trisomy 21, the most frequent genetic disorder with hard impact on public health, could provide an interesting model for the role of aneuploidy in the cell cycle alterations, leukemia, tumors and cancer and may be considered as a developmental genetic model to study and decipher the genetic networks involved in these different associated diseases. Some chromosome 21 genes play important roles in cell cycle and cell growth and could with the recent progress in the developmental genetics promise significant progress in the elucidation of the molecular mechanisms involved in the Down syndrome associated diseases related to leukemogenesis, tumorigenesis and cancerigenesis in the perspective of the identification of the genetic targets for drugs and therapeutics.

\section{References}

1. Rachidi M, Lopes C (2007) Mental retardation in Down syndrome: From gene dosage imbalance to molecular and cellular mechanisms. Neuroscience Research 59:349-369. [Crossref]

2. Okuda T, van Deursen J, Hiebert SW, Grosveld G, Downing JR (1996) AML1 the target of multiple chromosomal translocations in human leukemia, is essential for normal fetal liver hematopoiesis. Cell 84: 321-330. [Crossref]

3. Song WJ, Sullivan MG, Legare RD, Hutchings S, Tan X, et al. (1999) Haploinsufficiency of CBFA2 causes familial thrombocytopenia with propensity to develop acute myelogenous leukaemia. Nature Genet 23: 166-175. [Crossref]

4. Bourquin JP, Subramanian A, Langebrake C, Reinhardt, D, Bernard O et al. (2006) Identification of distinct molecular phenotypes in acute megakaryoblastic leukemia by gene expression profiling. Proc Natl Acad Sci 103: 3339-3344. [Crossref]

5. Nakagawa M, Shimabe M, Watanabe-Okochi N, Arai S, Yoshimi A, et al. (2011) AML1/ RUNX1 functions as a cytoplasmic attenuator of NF-I ${ }^{\circ} \mathrm{B}$ signaling in the repression of myeloid tumors. Blood 118: 6626-6637. [Crossref]

6. Adam L, Vadlamudi RK, McCrea P, Kumar R (2001) Tiam1 overexpression potentiates heregulin-induced lymphoid enhancer factor-1/beta-catenin nuclear signaling in breast cancer cells by modulating the intercellular stability. J Biol Chem 276: 28443-28450. [Crossref]

7. Malliri A, vander Kammen RA, Clark K, Van DV, Michiels F et al. (2002) Mice deficient in the Rac activator Tiam1 are resistant to Ras-induced skin tumours. Nature 417: 867-871. [Crossref]
8. Morikawa K, Walker SM, Jessup JM, Fidler, IJ (1988) In vivo selection of highly metastatic cells from surgical specimens of different primary human colon carcinomas implanted into nude mice. Cancer Res 48: 1943-1948. [Crossref]

9. Minard ME, Herynk MH, Collard JG, Gallick GE (2005) The guanine nucleotide exchange factor Tiam1 increases colon carcinoma growth at metastatic sites in an orthotopic nude mouse model. Oncogene 24: 2568-2573. [Crossref]

10. Liu L, Zhang Q., Zhang Y, Wang S, Ding Y (2006) Lentivirus-mediated silencing of Tiam 1 gene influences multiple functions of a human colorectal cancer cell line. Neoplasia 8: 917-924. [Crossref]

11. Chen B, Ding Y, Liu F, Ruan J, Guan J, et al. (2012) Tiam1, overexpressed in most malignancies, is a novel tumor biomarker. Mol Med Rep 5: 48-53. [Crossref]

12. Li Z, Liu Q, Piao J, Hua F (2016) Clinicopathological implications of Tiam1 overexpression in invasive ductal carcinoma of the breast. BMC Cancer 16: 681. [Crossref]

13. Rachidi M, Lopes C, Charron G, Delezoide AL, Paly E et al. (2005) Spatial and temporal localization during embryonic and fetal human development of the transcription factor SIM2 in brain regions altered in Down syndrome. Int J Dev Neurosci 23: 475-484. [Crossref]

14. DeYoung MP, Tress M, Narayanan R (2003) Identification of Down's syndrome critical locus gene SIM2-s as a drug therapy target for solid tumors. Proc Natl Acad Sci U S A 100: 4760-4765. [Crossref]

15. DeYoung MP, Tress M, Narayanan, R (2003b) Down's syndrome- associate SingleMinded 2 gene as a pancreatic cancer drug therapy target. Cancer Letter 200: 25-31. [Crossref]

16. Aleman MJ, DeYoung MP, Tress M, Keating P, Perry GW et al. (2005) Inhibition of Single Minded 2 gene expression mediates tumor-selective apoptosis and differentiation in human colon cancer cells. Proc Natl Acad Sci 102: 12765-12770. [Crossref]

17. Meng X, Shi J, Peng B, Zou X, Zhang, C (2006) Effect of mouse Sim2 gene on the cell cycle of PC12 cells. Cell Biol Int 30: 349-353. [Crossref]

18. Halvorsen OJ, Rostad K, Oyan AM, Puntervoll H, Bo TH et al. (2007) Increased expression of SIM2-s protein is a novel marker of aggressive prostate cancer. Clin Cancer Res 13: 892-897. [Crossref]

19. Arredouani MS, Lu B, Bhasin M, Eljanne M, Yue W, et al. (2009) Identification of the transcription factor single-minded homologue 2 as a potential biomarker and immunotherapy target in prostate cancer. Clin Cancer Res 15: 5794-5802. [Crossref]

20. Nakamura K, Komatsu M, Chiwaki F, Takeda T, Kobayashi Y, et al. (2017) SIM21 attenuates resistance to hypoxia and tumor growth by transcriptional suppression of HIF1A in uterine cervical squamous cell carcinoma. Sci Rep 7: 14574. [Crossref]

Copyright: @2018 Rachidi M. This is an open-access article distributed under the terms of the Creative Commons Attribution License, which permits unrestricted use, distribution, and reproduction in any medium, provided the original author and source are credited. 